\title{
TOURIST-RECREATIONAL POTENTIAL OF THE AFFECTED OF METROPOLISES OF UKRANE ZONE
}

\author{
POTENCJAŁ TURYSTYCZNO-REKREACYJNY STREFY WPŁYWU \\ DUŻYCH MIAST UKRAINY
}

\author{
Viktor O. Yatsenko \\ Ph.D./ doctor of philosophyy \\ Author's Orcid number: 0000-0002-6054-729X \\ Kiev National University of Construction and Architecture \\ Department of Landscape and Tourist and Recreational Architecture \\ Katedra Krajobrazu i Architektury Turystyczno-Rekreacyjnej
}

\begin{abstract}
It considers the prerequisites for developing a methodology in order to create touristic recreational complexes based on resource capacities of local settlement systems (territorial communities) in Ukraine. Attention is given to the situation in the industry and its prospective capabilities to play a principal role in economic development of a number of territorial communities. It outlines a number of principles that need to be used when considering the process in the urban planning activities. It also provides a specific example of a strategic program of local system development with the touristic and recreational component as its basis. The research materials analyze the current state of affairs of urban planning activities in Ukraine, in particular, peculiarities of regional planning, using three largest cities and their suburbs as case studies. A number of negative trends have been discovered in the relations between the city and suburban area, that need to be resolved during the subsequent stages of designing to take into account the changes in the management system decentralization and development of territorial communities that will be interacting with the city on systemic positions.
\end{abstract}

Key words: agglomeration, big city, settlement system, urban planning activities, territorial community, local settlement system, touristic and recreational activities. 


\section{INTRODUCTION}

Today, the settlement system is considered to be a new stage of urban planning with the main task of uniting the problems of the city and environment due to emergence of an object - a territorial community (a local system of populated areas).

Social and political changes in Ukraine are characterized by restructuring of the political system of social institutions, changes in administrative and territorial structure, living conditions and labor relations, reassessment of the set of values, redistribution of powers and authority etc. Urban planning activities like no others have been at the crossroads of developments, advantages, hardships, suggestions and expectations of positive changes. There arose the necessity to revise design documentation at all levels starting with the General scheme of settlement. The emergence of a new territorial constituent that requires urban planning intervention - the amalgamated territorial communities or local settlement systems - has caused the need to revise the regulatory and legislative framework.

Political processes that drive changes in the planning structure development strategy at all levels of urban planning activities have an important significance as well.

The existing system of project activities is often deprived particularly of its systemic character, and therefore is not able to provide an exhaustive response to a number of changes that are taking place in the society and its requirements to the new forms of the quality of existence. The decentralization that is under way in the country, as well as changes in the administrative and territorial structure occurring in the actual reality have outpaced the theoretical and practical visions of the urban planning response to these processes. Therefore, spatial planning is a tool that is closest to the reality and allows developing a hypothesis and paradigm of its possible realization.

Recently, special attention has been paid to large cities and their influence zone in the sphere of territory planning according to the government policy. Decentralization processes have been encouraging their territorial growth even more. This is especially relevant for cities serving as centers of regional settlement systems, such as Kyiv, Lviv, Kharkiv, Dnipro, Odesa and others. Up to this time, there have been no theoretical definitions providing a clear explanation of a big city influence zone, suburban area, urban agglomeration etc. Therefore scientific research works have been to a significant degree based on conventionality of definitions.

In these circumstances, it would make sense to consider agglomeration, big city, and suburban area as a zone of "common interests of the city and region", as a unified spatial entity where society's daily living activities are developed, as a group form of settlement with definition of boundaries, authorities and tasks of urban planning and regional significance.

\section{ANALYSIS OF PUBLICATIONS ON THE TOPIC}

In Ukraine, project development activities have a rather firm and substantial basis that was developed back in the day by national architects. Thus in the XX century, a significant contribution into the theory and practice of the urban-planning school was made by works of D.I. Bohorad, A. Einhorn, H.I. Filvarov, and I.O. Fomin (Bogorad D.I., 1965; Fomin I.O., 1974; Fomin I.O., 1986), who introduced, in particular, systemic methods of regional planning. The works by M.M. Diomin and H.I. Lavryk (Dyomin M.M., 2005; Lavryk G.I., 1975) have become a methodological foundation for systemic methods in architecture and urban planning. The research works by Yu.M. Palekha, H.P.Pidhrushnyi, V.M.Vadimov, V.I.Myronenko, T.F.Panchenko, I.K.Bystriakov, V.V.Shulyk (Palekha Yu.M., 2010; Panchenko T.F., 2009; Shulyk V.V., 1997; Vadimov V.M., 2019) can be attributed to a number of specialized studies related to organization of activities at all levels. In their works, they considered the questions of transportation, industry, assessment of land, and natural potential for building recreational systems. The beginning of changes in XXI century was the search for new solutions both in the settlement system and at the level of communities themselves. 
At this period of time, the research efforts were mostly related to local aspects of environmental issues, preservation of nature, history, culture in the context of their capacities for creation of a future development strategy for local settlement systems - territorial communities. These studies include the works of H.Shulha, H.O.Osichenko and others.

Scientific works of M.M.Diomin, O.Synhaievska, V. M.Vadimov, T.F.Panchenko, Yu.M.Bilokon, I.O.Fomin, Yu.m.Palekha, H.H.Pidhrushnyi have been dedicated to research of systemic character of settlement at all levels. In the recent years, among the works of strategic importance, the research "Territorial planning in Ukraine" by V.S.Kuibida and Yu.M.Bilokon should be noted. It asserts that "european countries already possess experience in spatial development management" (Dyomin N.M., 1991; Filvarov G.I., 1990; Fomin I.O., 1998; Kuibidav.S., Bilokon Yu.M., 2009; Palekha Yu.M., 2010; Vadimov V.M., 2019).

Research of historical urban-planning assessments as a result of changes in administrative and territorial structure deserve special attention. Works of M.M.Habrel, I.O.Fomin, V.I.Nudelman, A.I.Stanislavskyi and others can be classified among such research efforts.

Foreign specialists, such as V.Gropius, L.Keeble, I.Freedman, K.Lynch, D.Harvey, and P. Hall should also be mentioned.

The specific character of the Ukrainian school lies in the deep study of separate directions in regional planning in the works of I.K.Bystriakov, H.P.Pidhrushnyi, Yu.M.Palekha, T.F.Panchenko, A.V.Hladkyi, and M.M.Kushnirenko. (Kushnirenko M.M., 2006; Palekha Yu.M., 2010; Panchenko T.F., 2009).

\section{OBJECTIVE}

This publication's objective is to demonstrate transformation of evolutionary studies in the sphere of regional and urban planning, characterize the real status of suburban territories in the process of decentralization and administrative and territorial changes in Ukraine. An attempt to find positive and negative sides in the complicated relations between the city and suburbs. And to suggest a strategy for agglomerating local systems of the local level of suburban zone into unified spatial, economic and social systems as one of the reactions to the generally uncontrolled process.

In further studies of the new settlement system stakeholder that was determined in the process of changes of the administrative and territorial subdivision of Ukraine, in particular, in studying the methodology of development of new approaches to the proposals for spatial development of local settlement systems based on conceptual principles and scientific substantiation of the new paradigm in urban planning activities. One of these approaches lies in engagement of significant resource capabilities for building up touristic and recreational network as a principal one in creation of a strategic program for territorial communities.

\section{MATERIALS AND METHODS}

Ukraine is a country with a relatively high level of urbanization: $67 \%$ of the population were living in urban settlements as of the beginning of 2000. (Kuibida V.S., Bilokon Yu.M., 2009).

Demographic forecasts that were used at that time envisaged a significant decrease in the population. And its reduction in industrially developed regions such as Dnipropetrovsk, Kharkiv, Luhansk, Odesa, and Zaporizhzhia was considered to be the main underlying reason. As of 2018, the forecasts largely came true due to a number of objective and subjective reasons. The country passed that threshold of 46 million in the downward direction.

Before the beginning of the 70 -ies of the XX century, the question of demographic character was more rhetorical than real, general plans were developed basing on the data significantly exceeding the actual figures. The analysis of region-planning works showed that they were implemented largely without taking into account the approved indicators. There 
appeared an idea of "complex regional planning" with developed recommendations that were approved by the State Committee for Construction of the Ukrainian Soviet Socialist Republic.

Almost for the last 30 years there have been significant changes in the settlement system and peculiarities of administrative structure, as well as quantitative indicators, economic strategy, environmental situation etc. More than 600 population centers have disappeared from the map of Ukraine. If we consider the main regions determined by the General Scheme, the following can be seen: Eastern region - economic decline, social changes, war; Central region - cardinal changes in the economic potential due to the loss of a large share of industry, migration processes and unreasonable growth of big cities; Western region - population outflow, migration abroad and almost complete decline of the economy, insufficient jobs and human resources; Southern region - significant loss of territories.

We are used to many processes taking place in the urban planning theory and practice. The growth of large cities, deterioration of the environment, migration of the population, devastation of territories and their common misuse constitute only an insignificant list of challenges in the current urbanization process. We have already agreed that the process of settlements agglomeration is connected with migration of the population of small inhabited localities in search of employment, better life, services, culture etc.

Frederick Lewis Allen has pointed out five main stages in the history of suburban areas development:

I-st - started in the late XIX century. With emergence of the railroad, country residents start commuting to towns for work. Inception of intensive migration processes. Distinguished development falls on 1900-1920.

II-nd - the 20-ies of XX century (emergence of personal vehicles). Construction of a large amount of country motor roads.

III-rd - 1930-1945 of the XX century - uneven and unstable situation in urban development.

IV-th - 1945-1980 of the XX century - an intensive stage driven by prefabricated construction, new materials, high demand for quickly-built accommodation.

V-th - 1980 - these days. Stratification of the society according to the level of income opens possibilities to build secondary residence in suburban areas, which significantly accelerates urbanization of suburban territories.

In 2020, it is planned to generally complete the decentralization process that started back in 2015. The new architectural elements of the settlement system - in particular, the amalgamated territorial communities - basically need to form and approve the strategic development plan, that is mostly based upon resource capacities, existing economic potential, information support and efficient system of management exercised by local self-government authorities.

The process of decentralization is raising serious questions of a new approach to the plans substantiated by the General Scheme in the domain of social and economic development, and a new type of urban-planning documentation is emerging at the local level. Currently, the created territorial communities are in a situation when their strategic vision of development has no relevant urban-planning concept.

Creation of a perspective evolution plan of a population center, district, region, as a rule, was based on the analysis of achievements, which was losing relevance as early as on the elaboration stage, therefore, the concept of spatial development of a local system should be based on the vision of the future, for the sake of which a way to its achievement is built. The perspective vision of the future is formed on the basis of its understanding by all community members and only then is it generalized by a professional team in the sphere of urban planning. 
The great opportunities for development of amalgamated communities as local systems are found in the natural potential and building up of touristic and recreational functions on its basis that will become a stimulus for economic capability.

Calling to foreign experience it is possible to trace the row of analogies in possibilities of forming, development and management of tourist-recreational network in the new terms of administrative-territorial device. The row of the programs, that became and successfully both the powerful ecological constituent of development as communities and states function on the whole, is created. So in Austria successfully the program of rural tourism functions "Vacation in a peasant court", that renders services in the sphere of rest, that are based on the traditional resources of culture, production, rest and others like that. The similar program "Rural hospitality" operates also in Sweden that combines in itself agriculture, environmental, animals, plants preservation and is based on the terms of participation of holiday-makers in the conduct of agriculture, residence in traditional farmsteads with self-service or receipt of services, and an acuests from activity goes to the improvement of equipping with modern amenities, engineering equipment and expansion of tourist infrastructure.

With its unique resources Ukraine has a possibility to raise the touristic and recreational industry to a significant level.

Ukraine has 70 thousand rivers and water reservoirs, two sea coasts, the Carpathian mountains, 6,737 specially allotted territories and natural reserve sites with an area exceeding $2.35 \mathrm{mln}$ hectares. $20.0 \%$ of this territory is occupied by national natural parks, $9.6 \%$ - by biosphere reserves, $17.2 \%$ - by regional landscape parks and many others. (Vadimov V.M., 2019; Decree of the Cabinet of Ministers of Ukraine of August 29, 2002).

Today, the great natural potential serves as the stimulus of economic development of local systems which will be able to restore growth and financial capacity of their existence.

Currently, in Ukraine, there is a large variety of touristic and recreational activities at different stages of development. These are water tourism, mountain hiking, ecological tourism, rural green tourism, educational tourism, business tourism, urban tourism to name a few.

However, development of the touristic and recreational industry that is able to become a foundation of economic stability of local systems does not meet its great potential and exceptionally convenient geopolitical location, if compared to the global and European scale. This is testified, for instance, by the main indicators of touristic flows in Ukraine and beyond its borders, that have unstable dynamics, and according to the data of the Ministry of Culture and Tourism, is within 2-3 mln tourists per annum, including 1-2 mln internal tourists. (Bilokon Yu.M., 2003).

The Kyiv agglomeration is the largest one in Ukraine, and could eventually form a single metropolis with Odesa, another city with a million-plus population. The combination of administrative functions with the functions of Odesa (port, sea, recreation...) in a single metropolis could give a significant impetus to the development of the settlement system and its transition to a higher level. The population of the Kyiv agglomeration was predicted to reach 3.0-3.2 million of residents in 2020. (Bilokon Yu.M., 2003). The Kyiv agglomeration presents the same trends as most major agglomerations of the world: rapid population growth, decline of manufacturing and industrial sphere, increasing social and environmental issues.

Today, in the strategy of creation of administrative-territorial communities as independent elements of settlement system, the city is forced to look for new approaches, in particular, attempts not to consider the city and suburban area in general, but regard it as an association of social and economic entities - territorial communities (group settlement systems at the local level). This approach most definitely corresponds to the term "planning of regulated development of urban agglomerations" introduced by I.O.Fomin in his work "Urban 
agglomeration planning (designing methodology)" as an opposite to the process of spontaneity and intensification of uncontrolled urbanization.

According to the last general plan of Kyiv (2002), which considered the city and suburban area comprehensively, the main tasks were as follows:

- improvement and further development of functional and planning structure that corresponds to the new status of Kyiv as the capital of an independent sovereign state;

- overcoming negative demographic trends in the acceleration of natural population growth and escalation of migration processes;

- the suburban area of Kyiv was defined as a new single administrative entity - "Kyiv Capital District".

This approach provided for an opportunity to achieve a more unified social, economic and territorial structure and ensure a more coordinated development of Kyiv and its area of influence.

In this situation, the task of the state is to direct the processes in order to create a regional touristic and recreational system with identification of available touristic resources; to determine the directions of functional use (cultural, educational, environmental and green tourism etc.); to legislatively ensure their effective protection, prevent uncontrolled processes of alienation and privatization; to develop and implement a strategic program of local system as a component of the regional one; to develop touristic and recreational activities of communities from the standpoint of evolution interests of social and urban planning peculiarities.

Formation of regional touristic systems is based on the areas of group accommodation zones of concentration of objects or natural resources, which in the new circumstances may become the unifying strategy for local settlement systems (territorial communities).

Part of the territorial presentations have been reflected in the already elaborated concepts of economic development of territorial communities, where the touristic and recreational sphere is one of the main strategic programs.

A case in point may be the strategy of the Koblevo amalgamated territorial community uniting 10 inhabited localities with a population of 7,266 people (as of 2017).

Economic specialization for the period of amalgamation: touristic sector, agriculture, recreational territories, recreation facilities, Tylihulskyi regional landscape park and others.

The strategy of development of recreational prospects for economic development is also included in Velykodymerska amalgamated territorial community as a prospective object in the influence area of the large metropolitan city of Kyiv and atc of the urban-type settlement Borodianka. (Fig. 1).

In their development, the touristic and recreational activities have to follow the principles of sustainable development of local settlement systems for every separate goal as well as common goals of economic and environmental improvement of regions and the country.

These principles may be as follows: the main purpose of activities is to be aimed at preservation of nature; upbringing the culture and sensitive attitude of the society to the history, nature etc.; the new administrative units - territorial communities - need to be less dependent on the unbalanced use of land; all the processes have to be carried out basing on the environmental strategy of preservation; high quality structure and services provision as a stimulus of development; the activities are to be aimed at long-term period of cooperation of all spheres both in public and private sector and creation of investment attractiveness of territorial communities. 


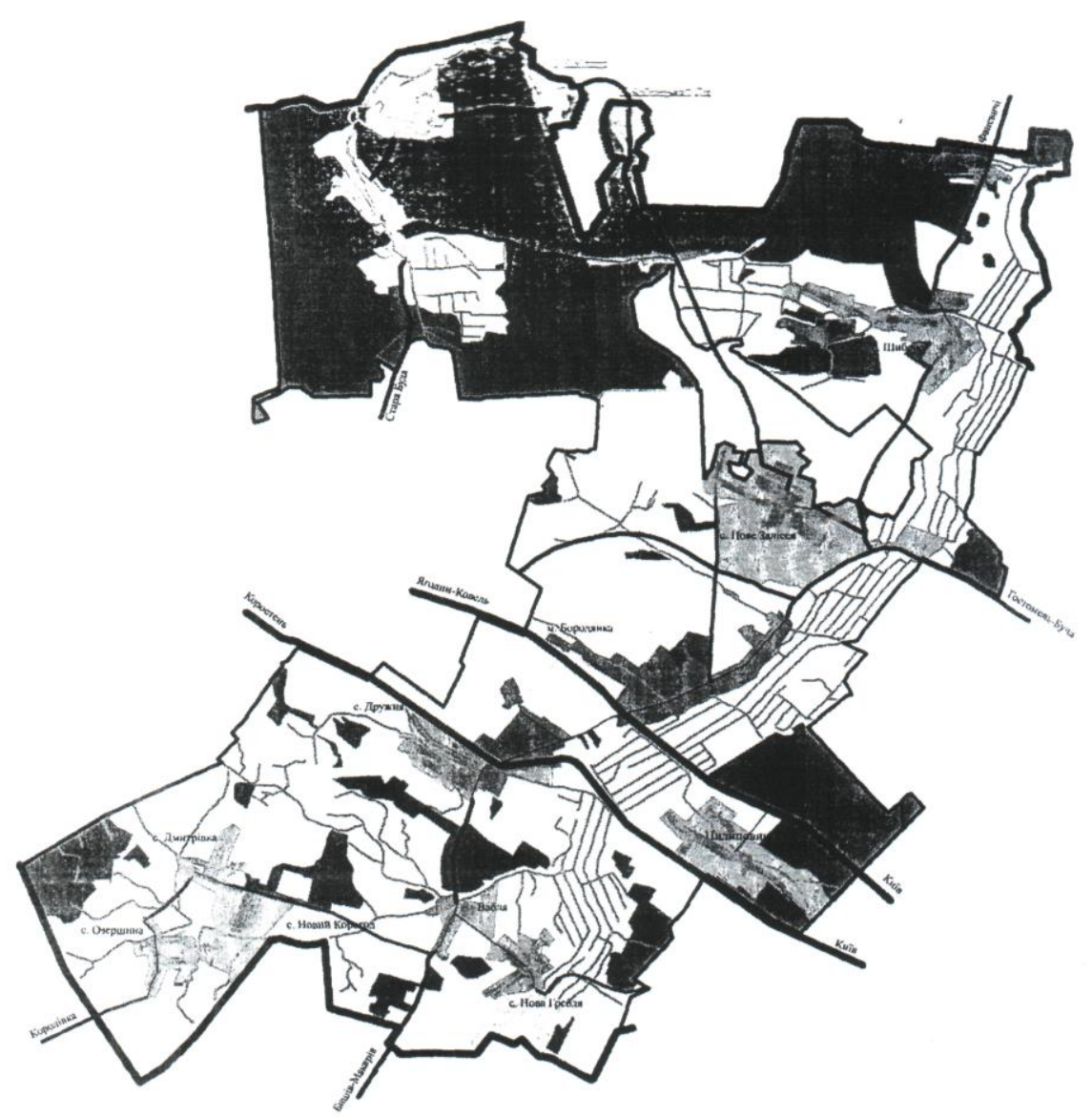

Fig. 1. Recreational potential of Borodianska ATC. Source: the scheme developed by Viktor O. Yatsenko

Today, the main positions in the urban planning activities are occupied by land interests, and this, as nothing else, is influencing the natural environment that serves as basis for the touristic and recreational system of the new settlement elements.

Therefore, understanding of decentralization ideology as a reform requires evaluation of current cooperation of the governance system as well as social and economic situation in the society and helps identify strategic sections of sustainable development of the settlement system taking into account all the domains of activities:

- to trace in historical perspective the peculiarities of formation of the country's administrative and territorial division and a relevant system of management of each separate system;

- to offer a methodological foundation that has to be based on governance, complex cooperation of all spheres of the society, determined taxonomic territorial units owned by them;

- to create a model of vertical regulation and horizontal management of all the spheres of society life, unlike the existing statutory, legislative, governance and supervisory vertical structure;

- to identify factors that can influence reformation of the existing system of local selfgovernance into a transformed system of group forms of settlements depending on strategic program;

- to offer tools of structural organization of space as an object of urban planning, zoning and regionalization of territory taking into account the territorial community as a new 
local level stakeholder with a special type of economic strategy for touristic and recreational activities.

The agglomeration becomes a factor of external influence, which largely dictates the conditions of the system operation forcing it to adapt to the city conditions and requirements. This influence is especially evident in the suburban area, where territorial communities have essentially lost their historical identity in economic development.

Development of the compensatory capabilities for the both subjects should become one of the ways to adapt the impact of the large city agglomeration forces and reactive changes in local level systems in order to maintain their structure. Otherwise, the lower level system (territorial community) will be forced to make a phase transition, changing its structure and nature of functioning. With too rapid and significant changes in the external environment, the local level system may totally collapse, and the territorial community may be disbanded or attached to another system.

Thus the existing urban-planning documentation is losing its untouchability and incorporated implementation guidelines without taking into account the dynamics of social changes, that have to be built-in as possible ones on the way to achievement of the ultimate objective. Collective substantiation of the ultimate objective determines specific structures responsible for its implementation and building of specific steps in the system that governs its achievement.

The main instrument for carrying out management and oversight should be monitoring of all processes for anticipatory identification of possible issues and probable mitigation of their negative impact.

That is why today in Ukraine the planning of local systems' territories provides for dedicated activities with elaboration of a space development strategy in order to create and support full-fledged living environment. As a result, approval of the newly elaborated urban planning documentation does not mean any automatic change of functional zoning of local system's territory, real changes can take place only upon initiative of an amalgamated territorial community as a user and owner of a relevant territory confirmed by land-surveying documentation. And this is guaranteed by harmonization of statutory, legislative and governance spheres according to a principle stating that they all belong to urban planning legislation, i.e. to spatial planning.

\section{RESULTS AND THEIR DISCUSSION}

The result of the study is an attempt to consider the relationship of the city and the surrounding territory not from the standpoint of suburbanization, which has gained significant momentum in Ukraine, but from the standpoint of a strategic joint process of streamlining all factors: economic, political, environmental etc.

It is an attempt to identify the main strategic aspects that may subsequently be introduced into the process of forming the relationship of the city and surrounding territories. It is also an attempt to avoid distribution of responsibilities, but to consolidate economic potentials, natural resources, social desires, demographic situation and political will to form decentralization processes and a new administrative system based on the rights of laws in accordance with regulatory requirements.

Therefore, the search for conceptual solutions of balanced formation of local settlement systems in the conditions of amalgamated territorial communities taking into account implementation of changes in the management domain, keeping balance of national, regional and local interests in land relations, possibilities of growth of local economy and satisfaction of social needs of the community is a relevant issue, and its resolution depends on the legislative and urban planning regulations, as well as on creation of modern statutory and methodological foundation for projecting activities. Modern decentralization policy gives the 
society a possibility to determine its capacities and responsibility, first of all, in the sphere of management of all the spatial planning processes as separate systems, as well as the country in general.

The modern policy of ecologization and preservation of natural environment provides a possibility for development of regional systems of touristic and recreational activities both for the country and for each local settlement system. It would be prospective to discuss particularly a comprehensive evaluation of resource capabilities of each territorial community and the possibility to develop adjacent regional programs.

\section{CONCLUSIONS}

The program of decentralization and the new administrative-territorial system, the organization of independent empowered territorial communities, in fact, is an attempt to define boundaries, to create associations of agglomeration relations based on the state of opportunities, desires from a particular person to the state program.

The modern policy of ecologization and preservation of natural environment provides a possibility for development of regional systems of touristic and recreational activities both for the country and for each local settlement system. It would be prospective to discuss particularly a comprehensive evaluation of resource capabilities of each territorial community and the possibility to develop adjacent regional programs.

Spatial planning as a management instrument for development of local systems, is aimed at fulfillment of the following tasks:

- the settlement system has to reduce to minimum the usage of territories with lack of responsibility for natural resources, as well as to optimize the existing system in terms of expenses for infrastructure development;

- coordination of development of local systems on the country's entire territory as a single economic, social, environmental organism - local system - district - region;

- prevention against emergence of regressing systems and creation of prospective chances of harmonious economic development.

The decentralization process in Ukraine is aimed at enlargement of the settlement system at the bottom level, in particular, formation of territorial communities as a local-level system providing the possibility for a more critical evaluation of the real resources for development.

To move from the desired trend to the agglomeration realized in the urban planning sense as an association of systems, it must receive physical boundaries, which will allow it to become an object of management, adjacent territories, taking into account the sufficient theoretical and practical experience of Ukrainian theory and practice of urban and regional planning. However, due to frequent changes in the social and political situation, the process of streamlining the territorial relations between the city and suburbs is chaotic. The chaotic character is reflected in the functional imbalance, environmental overload, lack of reconstructive processes in the engineering and transport systems, increased migration processes, low employment rates, and uneven social security. It is the strategy of the systematization principles complex that is able to improve the existing situation and implement a new strategy in the development of local settlement systems at the local level.

\section{BIBLIOGRAPHY}

Bilokon Yu.M. 2003. Regional planning (theory and practice). K.: Logos, 246 p.

Bogorad D.I. 1965. Constructive geography of district. Fundamentals of district planning. M.: Mysl (Idea), $407 \mathrm{p}$.

Dyomin M.M. 2005. General methods of metropolitan territories development in Ukraine. Scientifictechnical collection "Urban planning and spatial planning". K.: KNUBA, 21, p. 102-113. 
Dyomin N.M. 1991. Development management of town-planning systems. Kyiv: Budivelnyk, 184p.

Filvarov G.I. 1990. Patterns of spatial organization of social and production complex of the city. M., $49 \mathrm{p}$.

Fomin I. O. 1986. The city in the system of settlements. Kyiv: Budivelnyk, $112 \mathrm{p}$.

Fomin I.O. 1974. Urban development in industrial areas. Planning aspects. M.: Stroyizdat, 114 p.

Fomin I.O. 1998. Historical periodization of urban planning theory in Ukraine (20-40-ies). Regional problems of architecture and urban planning. Odesa: Astroprint, 2, p. 6-9.

Kuibida V.S., Bilokon, Yu.M. 2009. Territorial planning in Ukraine: European measures and national experience. Kyiv: Logos, p. 33-35.

Kushnirenko M.M. 2006. History of planning regulation of the Kyiv Agglomeration development. Experience and prospects of city development in Ukraine. Kyiv: Dipromisto, 10, p. 130-154.

Lavryk G.I. 1975. Methodological foundations of district planning. M.: Stroyizdat, 251 p.

Palekha Yu.M. 2010. Defining suburban areas of large cities - an urgent urban problem of today. Experience and prospects of development of cities in Ukraine. Kyiv: Dipromisto, 18, p. 5-14.

Panchenko T.F. 2002. Landscape and recreational zoning of the territory of Ukraine. K.: Dipromisto, 2, pp. 55-66.

Panchenko T.F. 2009. Social and economic factors of development of tourism, resorts and recreation in Ukraine. K.: Dipromisto, 16, pp. 24-44.

Perehuda le.V. 2013. Executive power in Ukraine. Political and legal aspects of modernization. Monograph. Kyiv: Logos, $315 \mathrm{p}$.

Shulyk V.V. 1997. Proposals for identification of prospective recreational territories. K.: KNUBA, 1, pp. 149-152.

Vadimov V.M. 2019. Peculiarities of spatial planning in conditions of integrated development of cities in Ukraine (Practical comment). Poltava: Dyvosvit, $235 \mathrm{p}$.

Administrative and territorial structure of Ukraine, 2002. History and modernity. Secretarial of the Cabinet of Ministers of Ukraine (Edited by V.H. Yakuba). K.

Decree of the Cabinet of Ministers of Ukraine of August 29, 2002 No. 1291 "On ensuring implementation of the Law of Ukraine "On the General Scheme of planning of the territory of Ukraine".

\section{AUTHOR'S NOTE}

Architect, Ph.D., Professor, Kyiv national university of building and architecture, Faculty of architectural, Department of landscape and tourist-recreational architecture, Kyiv, Povitroflotsky Avenue, 31, 03680. Research interests: town-planning bases of development of the in-plant systems of settlement of the incorporated territorial communities.

Contact | Kontakt: $\underline{\text { murchik55@ukr.net }}$ 